\title{
CIMIENTOS, AUGE Y PROGRESIVO DESUSO DEL CONTROL DE CONVENCIONALIDAD INTERNO: VEINTE INTERROGANTES
}

\author{
FOUNDATIONS, GROWTH AND PROGRESSIVE DISUSED OF \\ CONVENTIONAL INTERNAL CONTROL: TWENTY INTERROGANTS
}

\section{Miriam Henríquez Viñas}

RESUMEN: El presente artículo plantea que la Corte Interamericana de Derechos Humanos no ha configurado un concepto unívoco de control de convencionalidad interno. Por el contrario, ha propuesto diversos significados que convierten este constructo en un "proceso en obras" que genera dudas. En tal sentido, el artículo identifica, en la jurisprudencia de los casos contenciosos de la última década, los sentidos atribuidos al control de convencionalidad, segmentando tres fases o etapas de desarrollo. Asimismo, reconoce en cada una de las etapas el destinatario, parámetro y objeto del control, verificando si tales elementos se expanden o se constriñen. También plantea una serie de interrogantes en torno a la precisión y coherencia de la noción control de convencionalidad.

Palabras clave: Control de convencionalidad, control de convencionalidad interno, jurisprudencia interamericana, Corte Interamericana de Derechos Humanos.

ABSTRACT: This article proposes that the Inter-American Court of Human Rights has not configured an univocal concept of conventional internal control. On the contrary, it has proposed several meanings that extend its control subjects, object and control parameter, which makes this construct za "process in works" that generates doubts. In this regard, it identifies, in the jurisprudence of the contentious cases of the last decade, the meanings attributed to the conventional internal control, segmenting three phases or stages of development. Likewise, it recognizes in each of the stages the subjects, parameter and object of the control, verifying if such elements expand or constrict. It also raises a series of questions about the precision and consistency of the meanigin conventional control.

Keywords: Conventional control, conventional internal control, inter-american jurisprudence, Inter-American Court of Human Rights.

Doctora en Ciencias Jurídicas, Universidad de Santiago de Compostela (España). Profesora de Derecho Constitucional y directora del Departamento de Derecho Público de la Universidad Alberto Hurtado, Santiago, Chile. Dirección postal: Cienfuegos 41, Santiago. Dirección electrónica: miriamhenriquez@yahoo.es - mhenriqu@uahurtado.cl

Este trabajo es parte de la investigación financiada por Fondecyt Regular de la Comisión Nacional de Investigación Científica y Tecnológica, bajo el No 1160953, con el título: "La (di)símil aplicación del control de convencionalidad por los tribunales nacionales". 


\section{INTRODUCCIÓN Y MÉTODO}

La noción del control de convencionalidad se ha edificado gradualmente a través de la jurisprudencia de la Corte Interamericana de Derechos Humanos (en adelante Corte Interamericana o Corte). Por ello, la hipótesis del presente trabajo es la siguiente: la Corte Interamericana no ha configurado un concepto unívoco de control de convencionalidad interno. Por el contrario, ha propuesto diversos significados que convierten este constructo en un "proceso en obras" que ha transitado tres etapas, generando dudas o cuestionamientos sobre su noción.

El cometido principal de este trabajo es: a) Identificar, en la jurisprudencia de los casos contenciosos de la última década, los sentidos atribuidos por la Corte Interamericana al instituto del control de convencionalidad interno, diferenciando sus distintas etapas de desarrollo; b) Reconocer en cada una de las etapas el destinatario, parámetro y objeto del control, verificando si tales elementos se expanden o se constriñen; y c) Plantear si tal desarrollo genera interrogantes en torno a la precisión y coherencia de la noción control de convencionalidad.

Para la confirmación de la hipótesis y la consecución del objetivo planteado se emplea la siguiente metodología: la revisión jurisprudencial de un universo acotado de sentencias de fondo de casos contenciosos emanadas de la Corte Interamericana de Derechos Humanos, entre septiembre del año 2006 (época del primer fallo que expuso el término "control de convencionalidad", es decir desde la dictación del fallo AlmONACid Arellano y otros vs. Chile) a agosto de 2017 (última sentencia dictada por la Corte al tiempo de la presentación de este trabajo). La definición por las sentencias de fondo dice relación con la estricta función de adjudicación que la Corte Interamericana realiza en estos casos. Por ende, se excluyen las resoluciones de supervisión de cumplimiento de las sentencias y las opiniones consultivas de la Corte.

Cada sentencia dentro de ese período ha sido considerada como una unidad de análisis en la que se rastreó el término la "control de convencionalidad". Se identificaron aquellos fallos que expresamente señalan "control de convencionalidad" en el cuerpo de la sentencia (no en las citas al pie) y se extrajo el pasaje textual o párrafo que lo menciona. De este grupo, se escogieron las sentencias en las que fueron reconocibles en el párrafo desagregado algunos de los siguientes criterios del control de convencionalidad: a) el destinatario o sujeto obligado a realizarlo, b) la forma de ejercicio, c) el parámetro o material controlante; y d) el objeto del control o material controlado. Todo respecto del control de convencionalidad interno, es decir aquel que corresponde realizarlo a los Estados. Por ello se prescindió de aquellas sentencias que suponían meras referencias al control de convencionalidad sin una identificación de todos o algunos de esos criterios; así como las expresiones relativas al control de convencionalidad externo, internacional o concentrado cuyo realizador es la misma Corte Interamericana.

Luego, se agruparon los párrafos desagregados para reconocer transversalmente semejanzas y diferencias según los criterios anunciados y los eventuales matices. Para ello, se partió del supuesto de que las decisiones del órgano de justicia internacional tienen al menos un valor de autoprecedente, es decir que lo afirmado por la Corte sobre el control 
de convencionalidad interno marca un entendimiento de esta institución que la vincula en los fallos sucesivos, a menos que explícitamente se afirme lo contrario. Luego, a partir de las semejanzas y reiteraciones se fijó una línea temporal que permitió distinguir tres etapas.

La división en etapas o fases surge de constatar que, entre septiembre del año 2006 a agosto del año 2017, la Corte Interamericana de Derechos Humanos dictó 187 sentencias en casos contenciosos ${ }^{1}, 36$ de ellas mencionaron la voz "control de convencionalidad" y señalaron su destinatario, la forma de su ejercicio, el parámetro y objeto del control de convencionalidad. Es decir, un $19,25 \%$ del universo total definido para este trabajo. Las sentencias iniciales fijaron con cierta uniformidad las bases del control de convencionalidad, dando lugar a la primera etapa. Luego, la mayor cantidad de sentencias sobre control de convencionalidad interno se concentraron en la segunda etapa, entre los años 2010 a 2012, época en que también se produjo una expansión de sus elementos centrales, principalmente aquellos relativos al destinatario y al parámetro del control. La tercera etapa, de 2013 a la fecha, se encuentra marcada por un progresivo decaimiento del uso del término.

Fijado así el enfoque del trabajo, los asuntos problemáticos se expondrán, a partir de la jurisprudencia contenciosa de la Corte Interamericana seleccionada, bajo el formato de preguntas sobre su configuración, solidez y coherencia. La pretensión no es brindar respuestas que resuelvan categóricamente las interrogantes planteadas, puesto que, como se dijo, este trabajo parte del supuesto de que el control de convencionalidad es un proceso que se ha ido configurando progresivamente por la Corte Interamericana. De esta forma, la referencia a los autores será excepcional para exponer las posiciones que la doctrina ha manifestado sobre las interrogantes planteadas, las que serán expuestas en las consideraciones finales.

\section{LOS CIMIENTOS DEL CONTROL DE CONVENCIONALIDAD: 2006-2009}

En la primera etapa del control de convencionalidad (2006-2009) se dictaron 6 sentencias que instalaron con cierta uniformidad -en comparación con la etapa siguientelos elementos configuradores del mismo ${ }^{2}$.

\section{A. UNA CONSTRUCCIÓN DE TIPO PRETORIANO Y DE NATURALEZA INDEFINIDA}

Desde 2003 la noción de control de convencionalidad se ha ido construyendo de manera progresiva por la jurisprudencia de la Corte Interamericana de Derechos Humanos, cuestión que puede constatarse al reconocer sus primeras alusiones en el voto concurrente

\footnotetext{
Comprensivas de sentencias de fondo, cuyo período de búsqueda abarca desde el 26 de septiembre de 2006 (correspondiente al caso Almonacid Arellano vs. Chile (2006) al 31 de agosto de 2017 (del caso Vereda La Esperanza vs. Colombia (2017).

2 Se trató de las sentencias correspondientes a los casos: 1) Almonacid Arellano y otros vs. Chile (2006), o Almonacid Arellano vs. Chile; 2) Trabajadores Cesados del Congreso (Aguado Alfaro y otros) vs. Perú (2006), o Trabajadores Cesados del Congreso vs. Perú; 3) La Cantuta vs. Perú (2006); 4) Boyce y otros vs. Barbados (2007), o Boyce vs. Barbados; 5) Heliodoro Portugal vs. Panamá (2008); y 6) Radilla Pachecho vs. México (2009).
} 
del juez García Ramírez en el caso Mrrna Mack Chang vs. Guatemala³, para luego ocupar un lugar central en las sentencias de la Corte, desde del fallo Almonacid Arellano vs. CHILE de 2006, que da inicio a la primera etapa reconocida en este trabajo.

La Corte Interamericana resolvió en el considerando 123 y 124 del emblemático fallo Almonacid Arellano vs. Chile, que el legislador está obligado a adecuar el Derecho interno a lo dispuesto en la Convención; sin embargo, la Corte Interamericana dispuso que cuando el legislador no cumple con este mandato, es deber de los jueces domésticos ejercer el control de convencionalidad.

El mandato de origen jurisprudencial al ejercicio del control de convencionalidad ha generado al menos las siguientes interrogantes: 1) ¿Es eficaz el control de convencionalidad de origen jurisprudencial en aquellos Estados que a nivel constitucional no han dispuesto cláusulas de apertura al Derecho Internacional de los Derechos Humanos?; 2) ¿Es viable el ejercicio del control de convencionalidad de origen jurisprudencial en aquellos Estados que no han dispensado valor de precedente a la jurisprudencia nacional, internacional e interamericana?; 3) ¿Está facultado un tribunal internacional para establecer, a través de sus decisiones, competencias -particularmente de control-a los órganos nacionales cuando estas no han sido conferidas constitucionalmente?

Por otro lado, en esta etapa -y en las sucesivas- se ha cuestionado la naturaleza del control de convencionalidad. Esto es: 4) ¿El control de convencionalidad es un control normativo, de compatibilidad, de regularidad, de conformidad, de adecuación, de consistencia, de congruencia, de interpretación conforme de las normas internas con relación a la Convención Americana y los precedentes de la Corte Interamericana?; o ¿El control de convencionalidad es simplemente la obligación de aplicar la Convención Americana y sus interpretaciones en la solución de los casos que se presentan a nivel interno?

Los fallos de la Corte Interamericana analizados en este período no explicitan la naturaleza del control de convencionalidad. Sin embargo, las afirmaciones que orientan su carácter apuntan principalmente a que se trata de un control de las normas internas en relación con la Convención Americana sobre Derechos Humanos y la interpretación que la Corte ha hecho de esta última. Así fue señalado en el caso Almonacid Arellano vs. Chile (2006): "En otras palabras, el Poder Judicial debe ejercer una especie de "control de convencionalidad" entre las normas jurídicas internas que aplican en los casos concretos y la Convención Americana sobre Derechos Humanos." En los mismos términos lo expresaron las sentencias de los casos La Cantuta vs. Perú (2006) y Boyce vs. Barbados (2007).

En ciertos casos, como Trabajadores Cesados del Congreso vs. Perú (2006), se señaló que tal control de convencionalidad debe ejercerse juntamente con el control de constitucionalidad y se eliminó la referencia a "una especie" de control de

La primera referencia al control de convencionalidad tuvo lugar en el voto concurrente razonado en el caso Myrna Mack Chang vs. Guatemala (2003) del juez García Ramírez. Luego, el mismo magistrado reiteró su postura en los casos Tibi vs. Ecuador (2004); RaXcacó Reyes vs. Guatemala (2005); y López Álvarez vs. HONDURAS (2006). 
convencionalidad: "En otras palabras, los órganos del Poder Judicial deben ejercer no solo un control de constitucionalidad, sino también "de convencionalidad" ex officio entre las normas internas y la Convención Americana”’

A partir de la sentencia del caso Radilla Pacheco vs. México (2009), la Corte Interamericana comenzó a señalar que se trata de un control de convencionalidad, sin más referencia a la "especie" de aquel, que debe ejercerse entre el objeto controlado y el objeto controlante, abandonando la mención a que tales normas controladas son las que "aplican en los casos concretos"s.

De la jurisprudencia contenciosa analizada, es posible deducir que el control de convencionalidad es para la Corte Interamericana un control normativo y no una mera aplicación de la Convención Americana y sus interpretaciones. Esto, a partir de los siguientes elementos que se extraen de las sentencias detalladas: a) Supone para el destinatario abstenerse de aplicar las normas internas cuando estas contrarían las normas de la Convención Americana y su interpretación. Así se explica la introducción de los párrafos analizados que señalan que la Corte es consciente que los destinatarios del control están obligados a aplicar las disposiciones vigentes en el ordenamiento jurídico; sin embargo ellos deben velar porque los efectos de las disposiciones de la Convención no se vean mermadas por la aplicación de leyes o interpretaciones "contrarias" a su objeto y fin; b) En ciertos casos se lo asimiló al control normativo de constitucionalidad; y c) En los casos en que se hizo referencia al efecto del control de convencionalidad, por ejemplo en la sentencia Almonacid Arellano vs. Chile (2006), se estimó la invalidez con efectos retroactivos de la norma inconvencional, "que desde un inicio carecen de efectos jurídicos", resultado propio de un control entre normas.

\section{B. Destinatario y FORMA DE EJERCICIO DEL CONTROL DE CONVENCIONALIDAD}

En relación con el destinatario del control de convencionalidad, la sentencia Almonacid Arellano y otros vs. Chile expresó que ejercer una "especie" de control de convencionalidad corresponde a "sus jueces, como parte del aparato del Estado" y en definitiva "al Poder Judicial". Luego de este icónico caso, las sentencias recaídas en los casos Trabajadores Cesados del Congreso vs. Perú (2006), La Cantuta vs. Perú (2006), Boyce vs. Barbados (2007), Radilla Pachecho vs. México (2009) refirieron de forma idéntica al "Poder Judicial" como sujeto obligado. La excepción a la formulación mencionada, la constituyó el caso Heliodoro vs. Portugal de 2008 en que se señaló a

\footnotetext{
Trabajadores Cesados del Congreso vs. Perú (2006) párrafo 128.

Del mismo tenor son las 22 sentencias de las etapas posteriores recaídas en los casos: ComUNidAD INDíGENA Xákmok Kásek s. vs. Paraguay (2010), Fernández Ortega vs. México (2010), Rosendo Cantu vs. México (2010), Ibsen Cárdenas vs. Bolivia (2010), Gomes lund vs. Brasil (2010), Cabrera García y Montiel Flores vs. México (2010), Gelman vs. Uruguay (2011), Chocrón vs. Venezuela (2011), López Mendoza vs. Venezuela (2011), Fontevecchia vs. Argentina (2011), Masacres de Río Negro vs. Guatemala (2012), Masacres de El Mozote vs. El Salvador (2012), Gudiel Álvarez vs. Guatemala (2012), Masacre de Santo Domingo vs. Colombia (2012), Mendoza vs. Argentina (2013), J. vs. Perú (2013), Liakat Ali Alibux vs. Surinam (2014), Personas dominicanas y haitianas vs. República Dominicana (2014), Rochac Hernández vs. El Salvador (2014), Chinchilla vs. Guatemala (2016), Trabajadores de la Hacienda Brasil Verde vs. Brasil (2016) y Miembros de la Aldea Chichupac vs. Guatemala (2016).
} 
"cada juzgador" como el destinatario, referencia que igualmente indica a quien ejerce la función judicial.

Cabe señalar que en el caso Boyce vs. Barbados, del año 2007, la Corte afirmó que tanto al Poder Judicial como a otros órganos jurisdiccionales les corresponde realizar el control de convencionalidad. En sus términos expresó que este es un deber de: "los tribunales de Barbados, incluso el Comité Judicial del Consejo Privado y ahora la Corte de Justicia del Caribe"6.

Lo dicho da cuenta que los destinatarios del control de convencionalidad en esta primera etapa fueron principalmente los jueces nacionales, que tienen a su cargo la salvaguarda de los derechos fundamentales. Esta afirmación, que describe al denominado control judicial difuso de convencionalidad, ha planteado las siguientes interrogantes: 5) ¿Es factible el control de convencionalidad en aquellos sistemas que no contemplan un control judicial difuso de constitucionalidad y por ende los jueces carecen de competencias para invalidar o inaplicar normas?; 6) En el hipotético caso de ser afirmativa la respuesta anterior ¿cómo opera y cuáles son los efectos del control de convencionalidad en aquellos sistemas en el que los tribunales de justicia no ejercen el control de constitucionalidad de las normas, sin embargo, son los garantes concretos de los derechos fundamentales?

Por otro lado, tempranamente la Corte Interamericana en la sentencia del 2006, recaída en el caso Trabajadores Cesados del Congreso vs. Perú, decidió no imponer una única forma de ejercicio del control de convencionalidad interno. Por el contrario, afirmó que el mismo "debe" realizarse por el Poder Judicial "ex officio y en el marco de sus respectivas competencias y de las regulaciones procesales correspondientes"'.

De este modo, la Corte señaló que el control de convencionalidad "debe" desarrollarse con dos condiciones: a) ex officio, esto significa -según el órgano de justicia internacional- que esta función no debe quedar limitada exclusivamente por las manifestaciones o actos de los accionantes en cada caso concreto, sino que debe ser ejercido por el órgano destinatario del control, aunque tampoco implica que esa revisión deba ejercerse siempre, sin considerar otros presupuestos formales y materiales de admisibilidad y procedencia de ese tipo de acciones; y b) en el marco de las respectivas competencias del órgano destinatario y de las regulaciones procesales correspondientes. Esta fórmula se reiteró en el caso Radilla Pachecho vs. México (2009).

Lo expresado ha generado las siguientes preguntas: 7) Dada la multiplicidad de tipos de procedimientos jurisdiccionales que tienen aplicación en los Estados ¿cuántas formas diferentes de control de convencionalidad pueden producirse? ; 8) ¿Las múltiples hipótesis que plantea el ejercicio del control de convencionalidad conducen a un entendimiento homogéneo de la institución a propósito de sus supuestos, procedimientos y consecuencias o efectos?

Boyce y otros vs. Barbados (2007) párrafo 78.

Trabajadores Cesados del Congreso vs. Perú (2006) párrafo 128. 


\section{Parámetro y obJeto del CONTROL De CONVENCIONALidAd}

A propósito del parámetro del control de convencionalidad, a partir del fallo Almonacid Arellano vs. Chile de 2006, se afirmó que este era la Convención Americana sobre Derechos Humanos y la interpretación que de esta efectúa la Corte, es decir, su jurisprudencia.

La expresión utilizada en esta primigenia sentencia, a propósito de la Convención Americana como material controlante, es la siguiente: "En otras palabras, el Poder Judicial debe ejercer una especie de "control de convencionalidad" entre las normas jurídicas internas que aplican en los casos concretos y la Convención Americana sobre Derechos Humanos".

En el fallo del caso Heliodoro Portugal vs. Panamá (2008), la Corte expresó que el control de convencionalidad exige considerar "el estándar internacional de protección de los derechos humanos", además de "los instrumentos internacionales".

Por otro lado, en este periodo, la Corte se refirió a la jurisprudencia interamericana como parámetro de control de convencionalidad de manera consistente. Así lo dijo en el caso Almonacid Arellano vs. Chile, atestiguando que en esta tarea el Poder Judicial debe tener en cuenta no solamente el tratado, "sino también la interpretación que del mismo ha hecho la Corte Interamericana, intérprete última de la Convención Americana”. En lo sucesivo, lo señalaron las sentencias dictadas en los siguientes 3 casos: La Cantuta vs. Perú (2006), Boyce vs. Barbados (2006) y Radilla Pachecho vs. México (2009).

Que la jurisprudencia interamericana sea parámetro de control de convencionalidad es probablemente una de las cuestiones que generaron más controversia en la época bajo estudio. Algunas de ellas se han reflejado en las siguientes interrogantes: 9) ¿La jurisprudencia interamericana tiene valor de precedente incluso en aquellos ordenamientos jurídicos en que la jurisprudencia carece de fuerza vinculante?; 10) ¿La interpretación formulada por la Corte Interamericana tiene el mismo valor que los preceptos de la Convención? O ¿̇la interpretación es superior a la Convención porque la Corte como intérprete final fija el sentido y alcance de sus proposiciones?; 11) Si la Corte es la intérprete última de la Convención ¿las opiniones consultivas también conforman la jurisprudencia interamericana vinculante en el control de convencionalidad?; 12) ¿Se instala la Corte como una fuente de producción normativa meta estatal que altera los sistemas nacionales de fuentes del Derecho?

Por otro lado, a propósito del objeto de control o material controlado, en el caso Almonacid Arellano vs Chile se afirmó por la Corte Interamericana que el control interno de convencionalidad alcanzaba a las "normas jurídicas internas". En el mismo sentido lo señalaron las sentencias de los casos La Cantuta vs. Perú (2006) y Boyce vs. Barbados (2007). Luego, en el caso Trabajadores Cesados del Congreso vs. Perú (2006) se simplificó la expresión a "normas internas"; que consideraría en un sentido amplio a

Tal fórmula fue reiterada en los siguientes 4 casos de esta etapa: Trabajadores Cesados del Congreso vs. Perú (2006), La Cantuta vs. Perú (2006), Boyce vs. Barbados (2006) y Radilla Pachecho vs. México (2009).

9 Heliodoro Portugal vs. Panamá (2008) párrafo 180 
la Constitución, a las leyes, a los reglamentos y a las demás normas que integren el orden jurídico nacional.

En el caso Heliodoro Portugal vs. Panamá de 2008, la Corte extendió el objeto del control desde las normas internas a "las normas o prácticas internas". En sus términos: "cada juzgador debe velar por el efecto útil de los instrumentos internacionales, de manera que no quede mermado o anulado por la aplicación de normas o prácticas internas contrarias al objeto y fin del instrumento internacional o del estándar internacional de protección de los derechos humanos" ${ }^{10}$. Esta última aseveración ha planteado la siguiente duda sobre el alcance del material controlado: 13) ¿El control de convencionalidad se ejerce respecto de las normas y también de los hechos internos? ¿Conserva en este sentido su naturaleza de control de compatibilidad o consistencia entre normas?

Según lo expresado, en esta primera etapa, el control de convencionalidad fue concebido como un control de compatibilidad con perfiles más o menos estrictos, que debía realizar el Poder Judicial, ex officio y en el marco de sus respectivas competencias y regulaciones procesales correspondientes, de las normas internas en relación con la Convención Americana y la interpretación que de esta última realiza la Corte Interamericana.

\section{AUGE Y AMPLIACIÓN DEL CONTROL DE CONVENCIONALIDAD} 2010-2012

En la segunda etapa del control de convencionalidad, que comprende los años 2010 a 2012, se dictaron 17 sentencias, varias de las cuales extendieron los elementos configurados en la fase anterior ${ }^{11}$.

\section{A. Destinatario y Forma De EJERCICIO DEL CONTROL DE CONVENCIONALIDAD}

Respecto al destinatario del control de convencionalidad, 6 sentencias de esta segunda etapa, principalmente del año 2010, continuaron la referencia iniciada en Almonacid Arellano vs. Chile (2006) al "Poder Judicial"12. A su vez, la sentencia Vélez

10 Heliodoro Portugal vs. Panamá (2008) párrafo 180.

11 Las sentencias corresponden a los casos: 1) Comunidad Indígena Xákmok Kásek vs. Paraguay (2010); 2) Fernández Ortega y otros vs. México (2010), o Fernández Ortega vs. México; 3) Rosendo Cantu y otros vs. México (2010), o Rosendo Cantu vs. México; 4) Ibsen Cárdenas e Ibsen Peña vs Bolivia (2010), o Ibsen Cárdenas vs. Bolivia; 5) Vélez loor vs. Panamá (2010); 6) Gomes lund y otros (“Guerrilha do Araguaia”) vs. Brasil (2010), o Gomes Lund vs. Brasil; 7) Cabrera García y Montiel Flores vs. México (2010), o Cabrera García y Montiel Flores vs. México; 8) Gelman vs. Uruguay (2011); 9) Chocrón Chocrón vs. Venezuela (2011), o Chocrón vs. Venezuela; 10) López Mendoza vs. Venezuela (2011); 11) Fontevecchia y D`Amico vs. Argentina (2011), o Fontevecchia vs. Argentina; 12) Atala Riffo y niñas vs. Chile (2012), o Atala Riffo vs. Chile; 13) Furlan y familiares vs. Argentina (2012), o Furlan vs. Argentina; 14) Masacres de Río Negro vs. Guatemala (2012); 15) Masacres de El Mozote y lugares aledaños vs. El Salvador (2012), o Masacres de El Mozote vs. El Salvador; 16) Gudiel Álvarez y otros (“Diario Militar”) vs. Guatemala (2012), o Gudiel Álvarez vs. Guatemala; y 17) Masacre de Santo Domingo vs. Colombia (2012).

12 Así se reflejó en los casos Comunidad Indígena Xákmok Kásek vs. Paraguay (2010), Fernández Ortega vs. México (2010), Ibsen Cárdenas vs. Bolivia (2010), Rosendo Cantú vs. México (2010) y Gomes Lund vs. BRASIL (2010). 
Loor vs. Panamá de 2010 señaló como obligado -al igual que el caso Boyce vs. BARBAdos (2007) - tanto al Poder Judicial como a otros órganos jurisdiccionales: "los órganos de cualquiera de los poderes cuyas autoridades ejerzan funciones jurisdiccionales"13.

Fue a finales del 2010, en el caso Cabrera García y Montiel Flores vs. México, que la Corte incluyó entre los sujetos encargados de ejercer el control de convencionalidad no solo a los jueces sino también "a los órganos vinculados a la administración de justicia en todos los niveles" ${ }^{\prime 4}$, como podrían serlo, a modo ejemplar, los secretarios judiciales, los tribunales electorales, el Ministerio Público, el Consejo de la Magistratura, entre otros ${ }^{15}$.

Esta ampliación ha generado la siguiente incertidumbre: 14) ¿Cuáles son los órganos vinculados a la administración de justicia? ¿Esta vinculación es orgánica o funcional? ¿Cuál es el ámbito de extensión de "a todos los niveles"?

La misma sentencia del caso Cabrera García y Montiel flores vs. México prosiguió su razonamiento sobre la autoridad obligada por el control de convencionalidad con particular alusión a los tribunales constitucionales que, en ciertos ordenamientos, son órganos independientes del Poder Judicial. En este caso, a partir del párrafo 226 de la sentencia, la Corte mencionó a los "tribunales de la más alta jerarquía en la región" que han ejercido el control de convencionalidad y destacó a la "Sala Constitucional de la Corte Suprema de Justicia de Costa Rica, al Tribunal Constitucional de Bolivia, a la Suprema Corte de Justicia de República Dominicana, al Tribunal Constitucional del Perú, a la Corte Suprema de Justicia de la Nación de Argentina y a la Corte Constitucional de Colombia" ${ }^{\prime 6}$. En el mismo sentido lo señalaron los casos Chocrón vs. Venezuela (2011) y López Mendoza vs. Venezuela (2011) ${ }^{17}$. En el caso Atala Riffo vs. Chile (2012), se agregaron además los siguientes tribunales o cortes: "la Suprema Corte de la Nación de México y la Corte Suprema de Panamá”18, que luego se replicaron en Furlán vs. Argentina (2012).

La mención a los Tribunales Constitucionales ha expuesto los siguientes entresijos: 15) ¿Es viable el control de convencionalidad en aquellos ordenamientos en que el control de constitucionalidad se encuentra concentrado en un órgano que carece de competencias protectoras directas de los derechos fundamentales?; 16) ¿Están facultados los Tribunales Constitucionales para ejercer el control de convencionalidad en aquellos ordenamientos en los que no se reconoce constitucionalmente un bloque de convencionalidad, pues los tratados no tienen atribuido rango constitucional o supraconstitucional?; 17) ¿El control de convencionalidad reemplaza la noción de bloque constitucional de derechos?

\footnotetext{
13 Vélez loor vs. Panamá (2010) párrafo 287.

14 Cabrera García y Montiel Flores vs. México (2010) párrafo 225.

15 Así también lo expresaron otras 8 sentencias de la etapa, correspondientes a los casos: ChOCRÓN Vs. VENEzuela (2011), López Mendoza vs. Venezuela (2011), Fontevecchia vs. Argentina (2011), Atala Riffo vs. Chile (2012), Furlan vs. Argentina (2012), Masacres de Río Negro vs. Guatemala (2012), Gudiel Álvarez vs. Guatemala (2012) y Masacre de Santo Domingo vs. Colombia (2012).

16 Cabrera García y Montiel Flores vs. México (2010) párrafo 226 a 232.

17 Chocrón Chocrón vs. Venezuela (2011) párrafo 165 a 171; 13; López Mendoza vs. Venezuela (2011) párrafo 227.

18 Atala Riffo y niñas vs. Chile (2012) párrafo 283.
} 
En el caso Masacres de Río Negro vs. Guatemala de 2012, se aludió especialmente al Ministerio Público como destinatario del control de convencionalidad, señalando que, en esta tarea los jueces y órganos vinculados a la administración de justicia en todos los niveles, "como el ministerio público", deben tener en cuenta la Convención Americana y la jurisprudencia interamericana ${ }^{19}$. El Ministerio Público también fue señalado como obligado en el caso Gudiel Álvarez vs. Guatemala (2012), Mendoza vs. Argentina (2013) y Miembros de la Aldea Chichupac vs. Guatemala (2016).

En 2011, en el caso Gelman vs. Uruguay, la Corte Interamericana completó la ampliación del sujeto del control expandiéndolo a toda autoridad pública. Así lo señaló la sentencia en el párrafo 239: "La legitimación democrática de determinados hechos o actos en una sociedad está limitada por las normas y obligaciones internacionales de protección de los derechos humanos reconocidos en tratados como la Convención Americana, de modo que la existencia de un verdadero régimen democrático está determinada por sus características tanto formales como sustanciales, por lo que, particularmente en casos de graves violaciones a las normas del Derecho Internacional de los Derechos, la protección de los derechos humanos constituye un límite infranqueable a la regla de mayorías, es decir, a la esfera de lo "susceptible de ser decidido" por parte de las mayorías en instancias democráticas, en las cuales también debe primar un "control de convencionalidad (...), que es función y tarea de cualquier autoridad pública y no solo del Poder Judicial”20.

En el caso Masacres de El Mozote vs. El Salvador (2012), la Corte continuó esta línea y expresó que el control de convencionalidad "vincula a todos los poderes y órganos estatales en su conjunto" ${ }^{21}$.

La ampliación en estos términos, probablemente la más rotunda de todas las extensiones, ha planteado la siguiente duda: 18) ¿Es posible seguir considerando como control de convencionalidad aquel ejercido por órganos que, por su naturaleza, no cumplen funciones jurisdiccionales?

La Corte insistió en 16 fallos de esta etapa que el control de convencionalidad debe realizarse ex officio por el órgano correspondiente y en el marco de sus respectivas competencias y de las regulaciones procesales correspondientes ${ }^{22}$. Este elemento es probablemente uno de los más estables del control de convencionalidad, sin perjuicio de las variadas interpretaciones de su alcance.

\footnotetext{
Masacres de Río Negro vs. Guatemala (2012) párrafo 262.

Gelman vs. Uruguay (2011) párrafo 239.

Masacres de El Mozote y lugares aledaños vs. El Salvador (2012) párrafo 318.

22 Así lo hizo en las sentencias de los casos Comunidad Indígena Xákmok Kásek vs. Paraguay (2010), Fernández Ortega vs. México (2010), Rosendo Cantu vs. México (2010), Ibsen Cárdenas vs. Bolivia (2010), Vélez loor vs. Panamá (2010), Gomes lund vs. Brasil (2010), Cabrera García y Montiel Flores vs. México (2010), Gelman vs. Uruguay (2011), Chocrón vs. Venezuela (2011), López Mendoza vs. Venezuela (2011), Fontevecchia vs. Argentina (2011), Atala Riffo vs. Chile (2012), Furlan vs. Argentina (2012), Masacres de Río Negro vs. Guatemala (2012), Masacres de El Mozote vs. El Salvador (2012) y Gudiel Álvarez vs. Guatemala (2012).
} 


\section{B. Parámetro y objeto de CONTROL De CONVEnCiOnalidad}

La Convención Americana como parámetro de control de convencionalidad fue señalada en 15 sentencias de esta segunda época ${ }^{23}$.

En la sentencia del caso Ibsen Cárdenas vs. Bolivia de 2010, la Corte Interamericana amplió el material controlante desde la Convención Americana a los demás tratados que son de su competencia material. Así se manifestó en el párrafo 199 de la sentencia que dice: "El Tribunal recuerda que el objeto de su mandato es la aplicación de la Convención Americana y de otros tratados que le otorguen competencia" ${ }^{24}$. De este modo extendió el parámetro desde la Convención Americana al Protocolo de San Salvador, Protocolo Relativo a la Abolición de la Pena de Muerte, Convención para Prevenir y Sancionar la Tortura, Convención de Belém do Pará para la Erradicación de la Violencia contra la Mujer, Convención sobre Desaparición Forzada de Personas, y a los demás tratados que sobre la materia puedan quedar comprendidos dentro de las atribuciones de la Corte Interamericana.

Luego, siguiendo con la extensión, en la sentencia del 2012, del caso MASACRES DE Río Negro vs. Guatemala, en el párrafo 142, la Corte trató el corpus iuris internacional aludiendo, además de la Convención Americana, a la Convención sobre los Derechos del Niño: "En tal sentido, el Estado debe prestar especial atención a las necesidades y a los derechos de los niños, en consideración a su condición particular de vulnerabilidad. Asimismo, la Corte ha afirmado reiteradamente que "tanto la Convención Americana como la Convención sobre los Derechos del Niño forman parte de un muy comprensivo corpus juris internacional de protección de los niños que debe servir [...] para fijar el contenido y los alcances de la disposición general definida en el artículo 19 de la Convención Americana" ${ }^{25}$. Como se observa, la referencia expresa a tratados que no son de competencia material de la Corte es para "fijar el contenido y alcance" de las disposiciones de la Convención.

Más adelante, en el párrafo 262 de la misma sentencia, la Corte destacó al corpus iuris interamericano como parámetro del control de convencionalidad. Este estaría formado por la Convención Americana y otros tratados del sistema interamericano, listándolos de forma expresa, como la Convención Interamericana sobre Desaparición Forzada de Personas, la Convención Interamericana para Prevenir y Sancionar la Tortura y la Convención Interamericana para Prevenir, Sancionar y Erradicar la Violencia contra la Mujer "Convención de Belém do Pará". A juicio de la Corte, respecto de ellos debe ejercerse el control de convencionalidad, expresando así tal obligación: "Los jueces

\footnotetext{
23 En tal sentido lo expusieron los fallos dictados en los casos Comunidad Indígena Xákmok Kásek vs. Paraguay (2010), Fernández Ortega vs. México (2010), Rosendo Cantu vs. México (2010), Ibsen Cárdenas vs. Bolivia (2010), Vélez Loor vs. Panamá (2010), Gomes Lund vs. Brasil (2010), Cabrera García y Montiel Flores vs. México (2010), Gelman vs. Uruguay (2011), Chocrón vs. Venezuela (2011), López Mendoza vs. Venezuela (2011), Fontevecchia vs. Argentina (2011), Atala Riffo vs. Chile (2012), Furlan vs. Argentina (2012), Masacres de El Mozote vs. El Salvador (2012) y Masacre de Santo Domingo vs. Colombia (2012).

24 Ibsen Cárdenas e Ibsen Peña vs. Bolivia (2010) párrafo 199.

25 Masacres de Río Negro vs. Guatemala (2012) párrafo 142.
} 
y órganos vinculados a la administración de justicia en todos los niveles están en la obligación de ejercer ex officio un "control de convencionalidad" entre las normas internas y los tratados de derechos humanos de los cuales es Parte el Estado"26. En el mismo sentido, la sentencia dictada en el caso Gudiel vs. Guatemala (2012).

En consecuencia, el parámetro de control de convencionalidad alcanzó, tras su ampliación, a los tratados americanos de los cuales es parte el Estado, pero principalmente la Convención Americana sobre Derechos Humanos. La cuestión que se ha suscitado por esta expansión es: 19) ¿Los artículos 1.1, 2 y 29 de la Convención Americana, sindicados como el fundamento del control de convencionalidad, pueden interpretarse tan extensamente como para justificar tal ampliación a otros tratados internacionales de derechos humanos?

La jurisprudencia interamericana como parámetro de control de convencionalidad fue expresada en 15 sentencias de esta etapa, constituyendo un elemento estable de este periodo ${ }^{27}$.

Con relación al objeto del control, la Corte apuntó en 17 sentencias de esta etapa que el control de convencionalidad debía realizarse entre "las normas internas" y la Convención Americana, siendo también un elemento constante en este periodo ${ }^{28}$.

Así, la segunda etapa tuvo un afán y alcance totalizante, que en gran medida desnaturalizó la concepción estricta del control de convencionalidad concebido inicialmente como una verificación de no contradicción de las normas internas con la Convención Americana y su interpretación. Transformándose en el examen formulado por todo poder u órgano interno, respecto de todo acto interno, con relación a toda norma interamericana. De esta forma, el control de convencionalidad fue concebido por la Corte Interamericana como un control que debe ser ejercido por todos los poderes y órganos del Estado, pero principalmente por los órganos vinculados a la administración de justicia en todos los niveles, y, entre estos, los jueces nacionales. Por su parte, corresponde al obligado realizarlo ex officio y en el marco de sus respectivas competencias y de las regulaciones procesales correspondientes. Tal control de las normas internas debe realizarse con relación a los tratados del sistema interamericano de los cuales es parte el Estado,

26 Masacres de Río Negro vs. Guatemala (2012) párrafo 262.

27 Las sentencias son: Comunidad Indígena Xákmok Kásek vs. Paraguay (2010), Fernández Ortega vs. México (2010), Rosendo Cantu vs. México (2010), Ibsen Cárdenas vs. Bolivia (2010), Gomes Lund vs. Brasil (2010), Cabrera García y Montiel Flores vs. México (2010), Gelman vs. Uruguay (2011), Chocrón vs. Venezuela (2011), López Mendoza vs. Venezuela (2011), Fontevecchia vs. Argentina (2011), Atala Riffo vs. Chile (2012), Furlan vs. Argentina (2012), Masacres de Río Negro vs. Guatemala (2012), Gudiel Álvarez vs. Guatemala (2012) y Masacre de Santo Domingo vs. Colombia (2012).

28 Tales fueron: Comunidad Indígena Xákmok Kásek vs. Paraguay (2010), Fernández Ortega vs. México (2010), Rosendo Cantú vs. México (2010), Ibsen Cárdenas vs Bolivia (2010), Vélez loor vs. Panamá (2010), Gomes Lund vs. Brasil (2010), Cabrera García y Montiel Flores vs. México (2010), Gelman vs. Uruguay (2011), Chocrón vs. Venezuela (2011), López Mendoza vs. Venezuela (2011), Fontevecchia vs. Argentina (2011), Atala Riffo vs. Chile (2012), Furlan vs. Argentina (2012), Masacres de Río Negro vs. Guatemala (2012), Masacres de El Mozote vs. El Salvador (2012), Gudiel Álvarez vs. Guatemala (2012) y Masacre de Santo Domingo vs. Colombia (2012). 
pero principalmente con la Convención Americana sobre Derechos Humanos, y la interpretación que de estas normas ha formulado la Corte Interamericana.

\section{LA ESTABILIDAD Y PROGRESIVO DESUSO 2013-2017}

A partir de 2013, el número de sentencias que se dictaron por año disminuye en relación con aquellas pronunciadas en la etapa previa. Así, es posible contabilizar 13 sentencias en 5 años $^{29}$, sin registrarse sentencias que hicieran referencias -conforme al método adoptado- al control de convencionalidad en 2017.

En esta etapa se corrobora la naturaleza del control de convencionalidad como un control normativo. Así, el párrafo 284 del caso Atala Riffo vs. Chile (2012), la Corte afirma que se trata de un control de adecuación, y sigue la fórmula iniciada en Radilla Pacheco vs. México, que expone: "En conclusión, con base en el control de convencionalidad, es necesario que las interpretaciones judiciales y administrativas y las garantías judiciales se apliquen adecuándose a los principios establecidos en la jurisprudencia de este Tribunal en el presente caso." ${ }^{30}$ Igualmente, Furlan vs. Argentina (2012).

Por su parte, la Corte dijo en el fallo Andrade Salmón vs. Bolivia de 2016 que este tipo de control debe velar por la solución de las inconsistencias: "En este sentido, la jurisprudencia reciente ha reconocido que todas las autoridades de un Estado Parte en la Convención, tienen la obligación de ejercer un "control de convencionalidad", de forma tal que la interpretación y aplicación del derecho nacional sea consistente con las obligaciones internacionales del Estado en materia de derechos humanos"31.

\section{A. Destinatario del CONTROL}

Respecto al destinatario del control de convencionalidad, 6 sentencias continuaron con la mención originada en el caso Cabrera García y Montiel Flores vs. México (2010), en orden a que tal control corresponde no solo de los jueces sino también "a los órganos vinculados a la administración de justicia en todos los niveles"32.

29 Así, pueden mencionarse: 1) Mendoza y otros vs. Argentina (2013), o Mendoza vs. Argentina; 2) J. vs. Perú (2013); 3) Liakat Ali Alibux vs. Surinam (2014); 4) Norín Catrimán y otros (Dirigentes, miembros y activista del Pueblo Indígena Mapuche) vs. Chile (2014), o Norín Catrimán vs. Chile; 5) Personas dominicanas y haitianas eXpulsadas vs. República Dominicana (2014), o Personas dominicanas y haitianas vs. República Dominicana; 6) Rochac Hernández y otros vs. El Salvador (2014), o Rochac Hernández vs. El Salvador; 7) López Lone y otros vs. Honduras (2015), o López lone vs. Honduras; 8) Comunidad Garífuna de Punta Piedra y sus miembros vs. Honduras (2015), o Comunidad Garífuna vs. Honduras; 9) García Ibarra y otros vs. Ecuador (2015), o García Ibarra vs. Ecuador; 10) Chinchilla Sandoval vs. Guatemala (2016), o Chinchilla vs. Guatemala; 11) Trabajadores de la Hacienda Brasil Verde vs. Brasil (2016); 12) Miembros de la Aldea Chichupac y Comunidades Vecinas del Municipio de Rabinal vs. Guatemala (2016), o Miembros de la Aldea Chichupac vs. Guatemala; y 13) Andrade Salmón vs. Bolivia (2016).

30 Atala Riffo y niñas vs. Chile (2012) párrafo 284.

31 Andrade Salmón vs. Bolivia (2016) párrafo 93.

32 Así ocurrió en los casos Mendoza vs. Argentina (2013), J. vs. Perú (2013), Personas dominicanas y haitianas vs. República Dominicana (2014), López Lone vs. Honduras (2015), Comunidad Garífuna vs. Honduras (2015), Chinchilla vs. Guatemala (2016) y Miembros de la Aldea Chichupac vs. Guatemala (2016). 
A su vez, la Corte prosiguió la tendencia inaugurada en Gelman vs. Uruguay y dijo en 2014, en el caso Personas dominicanas y haitianas vs. República Dominicana: "en el ámbito de su competencia todas las autoridades y órganos de un Estado Parte en la Convención tienen la obligación de ejercer un control de convencionalidad"33, expresión que fue reiterada en el caso García Ibarra vs. Ecuador de 2015. Finalmente, el tribunal internacional insistió en la idea que los obligados por el control de convencionalidad son todos los poderes y órganos del Estado, en las sentencias del caso Rochac Hernández vs. SALVADOR de 2014: "Esta obligación vincula a todos los poderes y órganos estatales en su conjunto, los cuales se encuentran obligados a ejercer un control "de convencionalidad" ex offcio entre las normas internas y la Convención Americana" ${ }^{34}$ y en el caso TRABAJADORES de la Hacienda Brasil Verde vs. Brasil de 2016. Más ampliamente aún se señaló en el caso Andrade Salmón vs. Bolivia (2016), que expresó que "todas las autoridades de un Estado Parte en la Convención” deben ejercer el control de convencionalidad.

En un sentido que conjuga a todos los órganos del Estado, y entre ellos explícitamente a los jueces y órganos vinculados a la administración de justicia, destaca el caso Liakat Ali Alibux vs. Surinam de 2014, que indicó que el control de convencionalidad se encuentra a cargo de "todos los órganos del Estado, incluidos sus jueces y demás órganos vinculados a la administración de justicia en todos los niveles" 35 .

Igualmente se señaló que el control de convencionalidad debe realizarse ex officio y en el marco de sus respectivas competencias y de las regulaciones procesales correspondientes, en 8 fallos $^{36}$. Este elemento se mantuvo prácticamente inalterado en esta época.

Como se observa en esta etapa el tribunal internacional persistió en la tesis de que pueden ejercer el control de convencionalidad todos los poderes del Estado y los órganos vinculados a la administración de justicia en todos los niveles, ex officio y en el marco de sus respectivas competencias y de las regulaciones procesales correspondientes.

\section{B. Parámetro y objeto de Control de convencionalidad}

La Convención Americana como parámetro de control de convencionalidad fue señalada en 8 sentencias de la época ${ }^{37}$.

Empero, en los casos Miembros de la Aldea Chichupac vs. Guatemala (2016) y Mendoza vs. Argentina (2013) se prosiguió con el criterio iniciado en la etapa anterior en el caso Masacres de Río Negro vs. Guatemala de 2012, es decir que el material

\footnotetext{
Personas dominicanas y haitianas eXpulsadas vs. República Dominicana (2014) párrafo 311.

3 Rochac Hernández y otros vs. El Salvador (2014) párrafo 213.

5 Liakat Ali Alibux vs. Surinam (2014) párrafo 151.

36 Se trata de los casos Mendoza vs. Argentina (2013), J. vs. Perú (2013), Personas dominicanas y haitianas vs. República Dominicana (2014), Rochac Hernández vs. El Salvador (2014), Comunidad Garífuna vs. Honduras (2015), Chinchilla vs. Guatemala (2016), Trabajadores de la Hacienda Brasil Verde vs. Brasil (2016), Miembros de la Aldea Chichupac vs. Guatemala (2016).

37 Puntualmente en los casos J. vs. Perú (2013), Liakat Ali Alibux vs. Surinam (2014), Personas dominicanas y haitianas vs. República Dominicana (2014), Rochac Hernández vs. El Salvador (2014), López Lone vs. Honduras (2015), Comunidad Garífuna vs. Honduras (2015), Chinchilla vs. Guatemala (2016) y Trabajadores de la Hacienda Brasil Verde vs. Brasil (2016).
} 
controlante son los tratados americanos de los cuales el Estado es parte. Este último caso señaló: "los tratados de derechos humanos de los cuales es Parte el Estado", y luego especificó que los destinatarios del control "deben tener en cuenta no solamente la Convención Americana y demás instrumentos interamericanos"38.

La jurisprudencia interamericana como parámetro de control de convencionalidad fue expresada en 7 sentencias de esta etapa ${ }^{39}$.

Sin embargo, en esta fase la Corte comienza a explicitar el carácter vinculante de la jurisprudencia que genera. Una muestra de lo dicho, es la sentencia de 2013, Norín Catrimán vs. Chile, ocasión en que la Corte afirmó: "No obstante, la Corte recuerda que las autoridades judiciales deben aplicar los criterios o estándares establecidos en la jurisprudencia de la Corte (supra párrs. 307-312) en ejercicio del control de convencionalidad a fin de garantizar que la medida de prisión preventiva sea siempre adoptada de acuerdo a esos parámetros" ${ }^{40}$. También se expuso el carácter vinculante de la jurisprudencia interamericana -en el contexto del control de convencionalidad- en el caso López Lone vs. Honduras de 2015, cuyo párrafo 307 aseveró: "Por tanto, en la aplicación del nuevo régimen disciplinario, las autoridades internas están obligadas a tomar en cuenta las interpretaciones de la Convención Americana realizadas por la Corte Interamericana, en este y otros casos" ${ }^{41}$; y Comunidad Garífuna vs. Honduras del mismo año, cuyos considerandos 211 y 255 expresaron que "la Corte advierte la relevancia de la debida interpretación de la legislación y aplicación del control de convencionalidad, a la luz de la jurisprudencia de la Corte y estándares internacionales aplicables" en materia indígena, particularmente para garantizar los derechos de la propiedad colectiva indígena y tribal ${ }^{42}$.

Las menciones al carácter vinculante de la jurisprudencia interamericana como parámetro de control sugieren la última pregunta: 20) ¿Toda la jurisprudencia es obligatoria para los Estados, incluso aquella en la que el Estado no fue parte del litigio?

Con relación al objeto del control, la Corte apuntó en 9 sentencias de esta etapa que el control de convencionalidad debía realizarse entre "las normas internas" y la Convención Americana, manteniéndose este aspecto como uno de los elementos invariables de la configuración ${ }^{43}$.

\footnotetext{
38 Mendoza y otros vs. Argentina (2013) párrafo 221.

39 Este se plasmó en los casos: Mendoza vs. Argentina (2013), J. vs. Perú (2013), Personas dominicanas y haitianas vs. República Dominicana (2014), López Lone vs. Honduras (2015), Comunidad Garífuna vs. Honduras (2015), Chinchilla vs. Guatemala (2016) y Miembros de la Aldea Chichupac vs. Guatemala (2016)

40 Norín Catrimán y otros vs. Chile (2014) párrafo 464.

41 López Lone y otros vs. Honduras (2015) párrafo 307.

42 Comunidad Garífuna de Punta Piedra y sus miembros vs. Honduras (2015) párrafos 211 y 255.

43 De esta forma lo expresaron: Mendoza vs. Argentina (2013), J. vs. Perú (2013), Liakat Ali Alibux vs. Surinam (2014), Personas dominicanas y haitianas vs. República Dominicana (2014), López Lone vs. Honduras (2015), Comunidad Garífuna vs. Honduras (2015), Chinchilla vs. Guatemala (2016), Trabajadores de la Hacienda Brasil Verde vs. Brasil (2016) y Miembros de la Aldea Chichupac vs. Guatemala (2016).
} 


\section{CONSIDERACIONES FINALES}

La Corte Interamericana de Derechos Humanos no ha sostenido en su jurisprudencia un concepto unívoco de control de convencionalidad interno. Por el contrario, ha propuesto varios significados que amplían pretorianamente su destinatario, objeto y parámetro de control.

En una primera etapa, el control de convencionalidad fue concebido como un control de compatibilidad con perfiles estrictos, que debía realizar el Poder Judicial, ex officio y en el marco de sus respectivas competencias y regulaciones procesales correspondientes, entre las normas internas, por un lado; y la Convención Americana y la interpretación que de esta última realiza la Corte Interamericana, por el otro.

La segunda etapa del control de convencionalidad tuvo un alcance totalizante. El control de convencionalidad fue concebido como un control que debe ser ejercido por todos los poderes y órganos del Estado, pero principalmente por los órganos vinculados a la administración de justicia en todos los niveles. Por su parte, corresponde al obligado realizarlo ex officio y en el marco de sus respectivas competencias y de las regulaciones procesales correspondientes. Tal control debe ejercerse entre las normas internas, por un lado; respecto de los tratados de derechos humanos del sistema interamericano de los cuales es parte el Estado, pero principalmente la Convención Americana sobre Derechos Humanos, y la interpretación que de estas normas ha formulado la Corte Interamericana, por el otro.

Las cuestiones que se plantearon a propósito de esta ampliación fueron:

La tercera etapa corrobora la naturaleza del control de convencionalidad como un control normativo de las normas internas, que pueden ejercerlo todos los poderes del Estado y los órganos vinculados a la administración de justicia en todos los niveles, ex officio y en el marco de sus respectivas competencias y de las regulaciones procesales correspondientes. Tales normas internas se contrastan con los tratados americanos de los cuales el Estado es parte, y particularmente la Convención Americana; así como con la jurisprudencia interamericana, a la que se le atribuye expresamente valor vinculante.

De esta forma, es posible constatar que los distintos sentidos atribuidos al control de convencionalidad producen una serie de cuestionamientos, preguntas o interrogantes sobre su coherencia, algunas de las cuales se han expuesto en este trabajo. Corresponde ahora esbozar algunas respuestas, dando cuenta de las principales posiciones de la doctrina sobre el particular, así como nuestra opinión.

Las primeras tres preguntas se orientan a generar una reflexión sobre el origen jurisprudencial del control de convencionalidad y la factibilidad, eficacia y viabilidad de su ejercicio según los distintos diseños constitucionales de los Estados parte del sistema interamericano. Algunas Constituciones latinoamericanas son, por razón de la distribución de las funciones estatales y del contenido (cláusulas de apertura al Derecho Internacional de los Derechos Humanos) más propicias al ejercicio del control de convencionalidad.

A nuestro juicio, la Constitución Política, atendido su contenido, no favorece necesariamente el ejercicio del control de convencionalidad interno, toda vez que: a) no define la jerarquía de los tratados de derechos humanos; b) no explicita el criterio de interpretación conforme a los derechos consagrados en tratados ni el criterio de 
interpretación pro homine; c) no contiene una norma de incorporación de derechos implícitos; y d) no reconoce valor de precedente vinculante a la jurisprudencia nacional ni internacional. Todas disposiciones que en otras Constituciones han facilitado el ejercicio del control de convencionalidad ${ }^{44}$.

Sin embargo, cierto sector de la doctrina, estima que es suficiente para un adecuado ejercicio del control de convencionalidad la cláusula de apertura contenida en el artículo 5 inciso segundo de la Constitución Política, que actuaría "como cláusula constitucional de inclusión" del Derecho internacional de los derechos humanos, más particularmente de los derechos humanos, al Derecho interno ${ }^{45}$. Estos autores además fundan las facultades para desarrollar el mentado control en las disposiciones contenidas en los artículos 1.1, 2 y 29 de la Convención Americana.

La cuarta pregunta apunta a la controvertida naturaleza del control de convencionalidad ${ }^{46}$. Para algunos el control de convencionalidad es un control de compatibilidad entre normas, es decir de las normas internas respecto de las normas de la Convención Americana y la interpretación que de esta última realiza la Corte Interamericana ${ }^{47}$. Para otros, el control de convencionalidad es la aplicación de las normas que integran el parámetro de control ${ }^{48}$.

$44 \quad$ En el mismo sentido Núñez y Henríquez sostienen: "La ausencia de los elementos mínimos de articulación entre el Derecho internacional de los derechos humanos y el Derecho interno, especialmente la indefinición de la jerarquía constitucional de los tratados de derechos humanos, dificultan (sino es que imposibilitan) el ejercicio del control de convencionalidad por el Tribunal Constitucional chileno. Lo mismo podría acontecer con el Poder Judicial." Henríquez y Núñez (2017) p. 383.

Por su parte, Claudio Nash expresa en relación con la implementación del control de convencionalidad: "Finalmente, quiero destacar que como desafío de la implementación, el que en el derecho interno se debe ir avanzando hacia la aplicación directa de las normas del DIDH y su jurisprudencia. En los sistemas constitucionales donde se han constitucionalizado las normas internacionales su aplicación puede ser más fácil desde el punto de vista de los principios de jerarquía, coherencia interna y unidad del sistema jurídico codificado.” NASH (2013) p. 506.

45 En tal sentido Humberto Nogueira, Claudio Nash, Constanza Núñez, entre otros. Ver Nogueira (2015) p. 313. Nash (2012) pp. 48-51. Por su parte, Constanza Núñez extiende los fundamentos no solo al artículo 5, sino también a los artículos 1, 6, 7 y 19 de la Constitución Política, NúÑEz (2015) p. 165.

$46 \mathrm{Al}$ control de convencionalidad se le han atribuido al menos dos naturalezas distintas. Por un lado, como un control de contraste entre las normas internas y la Convención Americana y la interpretación que de esta realiza la Corte; y, por el otro, como la obligación de aplicar la Convención Americana y sus interpretaciones. El primer significado, a juicio de Karlos Castilla, constituiría una novedad para el sistema interamericano de protección de los derechos humanos; y el segundo no sería más que la observancia tradicional de los tratados internacionales como parte del Derecho interno, con una nueva denominación. El mismo autor se refiere a la primera operación como "falso control de convencionalidad"; y a la segunda como "garantía de tratados". Castilla (2014) p. 151.

47 A modo ejemplar, Juan Carlos Hitters expresa: "Surge de lo antedicho que la misión prístina de la Corte IDH está en llevar a cabo una inspección de convencionalidad 'comparando' la norma del derecho interno en relación a la convención y desentrañar si aquélla violenta a esta”. Hiтters (2009) p. 112.

Por su lado, Sagüés explica: "El objetivo del "control de convencionalidad" es determinar si la norma nacional enjuiciada a través de la Convención Americana sobre Derechos humanos, es o no "convencional", esto es, acorde con tal Convención (Corte Interamericana de Derechos Humanos, "Boyce y otros vs. Barbados", considerando 78). Si lo es, el juez la aplica. Caso contrario, no, por resultar "inconvencional”. Se trata, como se ha apuntado, de un análisis de confrontación normativa.” SAGǗs (2010) p. 127.

48 Por ejemplo, Humberto Nogueira expresa que el control de convencionalidad "ya existía previamente al caso Almonacid Arellano vs. Chile, lo que hace la CIDH en este caso es simplemente bautizar la obligación de los jueces nacionales como control de convencionalidad. De las sentencias de la $\mathrm{CIDH}$ antes precisadas pueden 
Desde nuestra perspectiva, con base en el análisis de la jurisprudencia de la Corte Interamericana, el control de convencionalidad es un control de compatibilidad entre normas aplicables en un caso concreto, que supone para el destinatario el deber de inaplicar -e invalidar si ostenta las competencias- la norma interna, permitiendo resolver antinomias. Esta obligación está matizada por su ejercicio en el marco de las respectivas competencias y de las regulaciones procesales correspondientes, en cuyo caso, en sistemas de control de constitucionalidad concentrado como el chileno, la facultad se restringiría al deber de los jueces de interpretar las normas internas conforme al parámetro de convencionalidad. En tal sentido, el control de convencionalidad no se trata de la simple aplicación de la normativa interamericana en los casos concretos que deben resolver los órganos estatales.

Las preguntas que siguen se refieren al ejercicio del control de convencionalidad en aquellos sistemas de justicia constitucional concentrada. Las dudas surgen porque el modelo propuesto por la Corte Interamericana sugiere fundamentalmente un control de convencionalidad judicial difuso. La doctrina en esta materia se divide entre quienes sostienen que cualquiera sea el modelo de justicia constitucional todos los jueces deben realizar el control de convencionalidad ${ }^{49}$; y otros afirman que dependiendo del modelo de justicia constitucional el examen de convencionalidad tendrá mayor o menor intensidad ${ }^{50}$.

determinarse las obligaciones de los jueces nacionales en términos de hacer cumplir en el derecho interno el respeto y garantía de los derechos humanos convencionalmente asegurados contra toda norma interna que los contravenga, dándoles a tales derechos un efecto útil." Tal obligación de los jueces consistiría, a juicio de Nogueira, en aplicar "como estándar mínimo los derechos y garantías contenidos en los derechos asegurados por la $\mathrm{CADH}$, lo que constituye un control diferente y distinto del control de constitucionalidad." NogueIRA (2012) pp. 1175 y 1180.

A su vez, Eduardo Ferrer Mac Gregor sostuvo, a propósito de la sentencia de cumplimiento del caso Gelman, que: "Esta ha sido entendida por la Corte IDH como una institución que se utiliza para aplicar el Derecho Internacional, principalmente el Derecho Internacional de los Derechos Humanos y específicamente la Convención Americana y sus fuentes, incluyendo la jurisprudencia de dicho Tribunal.” Ferrer Mac Gregor (2017) p. 37.

49 Allan Brewer-Carias postula: "Cuando afirmamos que todos los jueces nacionales tienen competencia para ejercer el control de convencionalidad, es para ejercerlo, de manera que aun en los países que tienen un sistema concentrado de control de constitucionalidad, y a pesar del control concentrado de constitucionalidad existente, todos los jueces y tribunales deben aplicar la Convención Americana y por ello están llamados a ejercer el control difuso de convencionalidad, lo que implica que en caso de incompatibilidad o conflicto entre una norma interna que deben aplicar parta resolver un caso concreto y normas de la Convención Americana deben dar preferencia a estas y desaplicar las normas de derecho interno contrarias a la Convención. BREWER-CARIAS, (2015) pp. 52 y 53.

50 Eduardo Ferrer formula una serie de distinciones atendiendo al grado de intensidad del control de convencionalidad y expresa: "En cambio, el grado de intensidad del "control difuso de convencionalidad" disminuirá en aquellos sistemas donde no se permite el "control difuso de constitucionalidad" y, por consiguiente, no todos los jueces tienen la facultad de dejar de aplicar una ley al caso concreto. En estos casos es evidente que los jueces que carecen de tal competencia, ejercerán el "control difuso de convencionalidad" con menor intensidad, sin que ello signifique que no puedan realizarlo "en el marco de sus respectivas competencias". Lo anterior implica que no podrán dejar de aplicar la norma (al no tener esa potestad), debiendo, en todo caso, realizar una "interpretación convencional" de la misma, es decir, efectuar una "interpretación conforme”, no solo de Ia Constitución nacional, sino también de la Convención Americana y de la jurisprudencia convencional." FERRER MAC Gregor (2011) p. 308. 
En nuestra opinión, en aquellos sistemas de justicia constitucional concentrado en un único órgano, como un Tribunal Constitucional, en el que los jueces carecen de facultades para invalidar e inaplicar normas, estos últimos no podrán anular, derogar, o inaplicar las normas internas inconvencionales. Solo les corresponderá, siguiendo a Ferrer Mac Gregor, realizar una interpretación conforme al parámetro de convencionalidad. Esta afirmación se condice con lo expuesto sobre la naturaleza del control de convencionalidad como un control de compatibilidad entre normas. Sin embargo, si la interpretación conforme no es posible por tratarse de una antinomia irresoluble, el órgano llamado a pronunciarse sobre la inconvencionalidad sería el Tribunal Constitucional. Empero, las condiciones constitucionales necesarias para que un Tribunal Constitucional sea considerado competente para tal declaración son la definición de la jerarquía constitucional o supraconstitucional de los tratados de derechos humanos y el reconocimiento explícito del valor vinculante de la jurisprudencia internacional. Aspectos ausentes del texto constitucional chileno.

Las últimas preguntas analizan la forma y los fundamentos del impacto del control de convencionalidad en el sistema de fuentes del Derecho de los Estados, principalmente porque este proceso presupone la superioridad jerárquica de la Convención Americana -y de los demás tratados de derechos humanos- y el valor de precedente vinculante de la jurisprudencia interamericana ${ }^{51}$. Desde la perspectiva de algunos autores, los fundamentos de este cambio se hallarían en el principio pacta sunt servanda y en que las obligaciones deben ser cumplidas de buena fe y que no puede invocarse para su incumplimiento el derecho interno (artículos 26 y 27 de la Convención de Viena sobre Derechos de los Tratados) y en los artículos 1.1, 2 y 29 de la Convención Americana. No obstante, otro sector de la doctrina cuestiona que estos cambios tengan fuente extraconstitucional ${ }^{52}$;

$51 \quad$ Así lo planteó tempranamente Néstor Pedro Sagüés: "Se parte tácitamente del supuesto de que el Pacto de San José de Costa Rica se encuentra por encima de todo el ordenamiento jurídico del Estado, sin omitir a la propia Constitución. El Pacto asume así, agrade o no esta conclusión, y por más que por algunos se la quiera edulcorar, condición de supraconstitucionalidad." SAGǗs (2010) p. 124. Por su parte, Eduardo Ferrer Mac Gregor se refiere a esta mayor jerarquía como supremacía convencional. Al respecto, sostiene que, considerando el compromiso de los Estados de respetar los derechos humanos previstos en los instrumentos internacionales, así como la creación de órganos y tribunales regionales con incidencia en los órdenes jurídicos nacionales, es lógico suponer la existencia de una "supremacía convencional", que otorga a la Convención Americana una prevalencia superior respecto de cualquier norma interna, incluidas las Constituciones nacionales. FerRER MaC-Gregor (2010) p. 185.

52 Por ejemplo, Karlos Castilla cuestiona el origen de control de convencionalidad: "De ser así, me gustaría saber ¿dónde está esa obligación?, ¿en qué parte de la $\mathrm{CADH}$, de los tratados interamericanos o de los tratados en general se establece que los Estados (vertiente Poder Judicial) están obligados a someter todas sus normas internas, incluida por supuesto la Constitución, al contenido de los tratados? Adquirir una obligación internacional, no significa ello, pues la decisión de cómo se organiza el sistema normativo interno es una decisión de cada Estado. Y advierto que la respuesta no es, ni la da el artículo 27 de la Convención de Viena sobre Derecho de los Tratados, pues basta ver los trabajos preparatorios de esta para entender las razones, origen, objeto y fin de esta norma, y comprobar que lo exigido por la Corte IDH es una obligación de imposible existencia bajo un análisis serio y cuidadoso de sus implicaciones, y más aún, de imposible aceptación por los Estados, pues no conozco a uno de éstos que esté dispuesto a reconocer or la simple aceptación del contenido de un tratado internacional, que la CADH y otros tratados tengan una posición supraconstitucional, pues insisto, esa es una decisión interna que solo los órganos legitimados y facultados para ello pueden tomar." Castilla (2013) p. 63. 
e incluso, en una posición más extrema, ciertos autores expresan que tal control de convencionalidad no tiene siquiera fuente en la Convención Americana ${ }^{53}$.

La temática más controvertida en este punto se refiere al supuesto valor vinculante erga omnes de la jurisprudencia interamericana como parámetro de control. En efecto, pocos dudan del valor jurídico vinculante inter partes de las sentencias definitivas recaídas en asuntos contenciosos; sin embargo, la doctrina se divide al momento de reconocerles eficacia vinculante con efectos erga omnes ${ }^{54}$. Este asunto ha llevado a ciertos autores a distinguir dos manifestaciones del control de convencionalidad. La primera, cuando existe una sentencia internacional dictada con carácter de cosa juzgada respecto de un Estado que ha sido parte en el caso sometido a la jurisdicción de la Corte Interamericana, denominada res judicata, cuyos efectos serían directos hacia las partes en la controversia internacional. La segunda, cuando el Estado no ha sido parte en el proceso internacional en que fue establecida determinada jurisprudencia, sin embargo, es parte de la Convención Americana, llamado res interpretata, siendo su efecto indirecto hacia todos los Estados Parte en la Convención Americana, basado nuevamente en la obligación de los Estados de respeto, garantía y adecuación (normativa e interpretativa) que establecen los artículos $1^{\circ} \mathrm{y}$ $2^{\circ}$ de la Convención Americana ${ }^{55}$.

Desde nuestra perspectiva, la jerarquía de los tratados de derechos humanos y la atribución del carácter de fuente formal del Derecho a la jurisprudencia que emana de los

En un sentido coincidente, Francisco Zúñiga analiza críticamente el control de convencionalidad y afirma que "carece de soporte real en un sistema de protección internacional-regional, como el interamericano y carece de soporte constitucional en nuestro país, por lo que dicha doctrina no es de recibo". Luego agrega que es la Constitución la que debe resolver el tema de la jerarquía de los tratados en el ordenamiento. También el autor expresa: "las sentencias de la Corte IDH, son obligatorias para el Estado, pero para los tribunales nacionales, tales sentencias no son fuente sino los tratados internacionales, cuando estos cumplen las condiciones de su aplicación directa." ZúNiga (2017) pp. 554-555.

53 Ximena Fuentes señala a propósito del considerando 124 del fallo Almonacid: "Es imposible no abrir los ojos con sorpresa al leer esta disposición. Una cosa es que el Estado pueda incurrir en responsabilidad internacional por el comportamiento de cualquiera de sus órganos, incluido el Poder Judicial, pero otra cosa muy distinta es señalar que los jueces chilenos tienen el deber de declarar tácitamente derogadas las disposiciones del derecho interno incompatibles con los tratados internacionales ratificados por Chile. Una decisión de esta naturaleza implica exigir una obligación de que los estados hagan autoejecutables las cláusulas de los tratados y de que le den el poder al juez de declarar sin efectos jurídicos las leyes contrarias a los tratados, incluso de oficio, en virtud de su obligación de ejercer ese llamado "control de convencionalidad". ¿Dónde se encuentra tal obligación en la Convención Americana? En ninguna parte. ¿¿Dónde se encuentra esa obligación en el derecho internacional general? En ninguna parte, por ahora.” FuENTES (2008), pp. 490 y ss.

54 Esta situación plantearía para algunos autores, como Néstor Pedro Sagüés, una interpretación mutativa por adición, pues la Corte habría agregado algo al contenido inicial del Pacto, aunque el texto literal de este no ha variado. SAGỨs, Néstor (2010) p. 126.

Otros autores, como Sergio García, matizan esta conclusión y aclaran que la interpretación únicamente tiene que ver con las normas. Lo que precisa García, cuando señala que "solo alcanza la interpretación de normas”, es que la interpretación atiende únicamente a la fijación del sentido de las disposiciones convencionales, el entendimiento general del precepto para todos los fines aplicativos que este pueda tener, no así a los extremos específicos del caso en que se hizo la interpretación, que solo conciernen al Estado y a la víctima que comparecieron en el juicio. García (2011) p. 139.

55 Ferrer (2014) pp. 656-657. 
tribunales nacionales o internacionales solo puede ser decidida por la Constitución de cada Estado.

Para finalizar, cabe citar al ex juez Sergio García Ramírez, iniciador del control de convencionalidad, quien llama la atención sobre un posible "descarrilamiento" de la figura: "Es deseable llegar pronto a coincidencias básicas en torno a las cuestiones que suscita el control de convencionalidad, a menudo fomentadas por el «entusiasmo» y las crecientes expectativas. Las coincidencias básicas permitirán que el control de convencionalidad alcance las mejores aplicaciones de que seamos capaces, adquiera razonable uniformidad en nuestra región y contribuya a la formación del ius commune, a la armonización y congruencia, a la definición plausible y admisible del orden jurídico y de sus garantías. Si esto no sucede, el riesgo es que se alimente la dispersión, surjan contradicciones en el interior de los países - no solo de los países entre sí- y decaiga la tutela continental de los derechos humanos" $" 56$.

Como se pretendió evidenciar en este trabajo, la falta de uniformidad y certeza de los contornos y naturaleza del control de convencionalidad, genera interrogantes sobre la precisión y coherencia de su noción y alcances.

\section{BIBLIOGRAFÍA CITADA}

Brewer-Carias, Allan (2015): "Estudios sobre el control de convencionalidad", VV.AA, Colección Estudios Jurídicos (No 109) (Caracas, Editorial Jurídica Venezolana) pp. 35112.

Castilla, Karlos (2013): “¿Control interno o difuso de convencionalidad? Una mejor idea: la garantía de los tratados", Anuario Mexicano de Derecho Internacional, Vol. XIII: pp. 51-97.

Castilla, Karlos (2014): "Control de convencionalidad interamericano: una mera aplicación del derecho internacional”, Revista Derecho del Estado (No 33), pp. 149-172.

Ferrer Mac-Gregor, Eduardo (2010): "El control difuso de convencionalidad en el Estado constitucional”, en Fix-Zamudio, Héctor, y Valdés, Diego (coord.), Formación y perspectiva del Estado mexicano (México, UNAM-El Colegio Nacional) pp. 155-188.

Ferrer Mac Gregor, Eduardo (2011): "Reflexiones sobre el control difuso de convencionalidad”, Opus Magna Constitucional Guatemalteco, Tomo III (Guatemala, Instituto de Justicia Constitucional) pp. 291-333.

Ferrer Mac Gregor, Eduardo (2013): "Eficacia de la sentencia interamericana y la cosa juzgada internacional: vinculación directa hacia las partes (res judicata) e indirecta hacia los Estados Parte de la Convención Americana (res interpretata) (Sobre el cumplimiento del Caso Gelman vs. Uruguay)", Revista Estudios Constitucionales, Año 11 (No 2) pp. 641-694.

Ferrer Mac Gregor, Eduardo (2017): "El control de convencionalidad en la jurisprudencia de la Corte Interamericana de Derechos Humanos (a una década de su creación: 2006-2016)", en Henríquez y Morales (coord.), El control de convencionalidad.

56 GarCía (2016) p. 175. 
Un balance comparado a 10 años de Almonacid Arellano vs. Chile (Santiago Der Ediciones) pp. 71-106.

Fuentes, Ximena (2008): "International and Domestic Law: Definitely an Odd Couple”, Revista Jurídica de la Universidad de Puerto Rico, Vol. 77 ( $\mathrm{N}^{\circ}$ 2) pp. 483-505.

García, Sergio (2011): "El control judicial interno de convencionalidad", Revista Ius, Vol. 5 (No 28) pp. 123-159.

GarCía, Sergio (2016): "Sobre el control de convencionalidad”, Pensamiento Constitucional, $\mathrm{N}^{\circ}$ 21: pp. 173-186.

Henríquez, Miriam y Núñez, José Ignacio (2017): "Control de convencionalidad en Chile: Un soliloquio en "El laberinto de la soledad", en Henríquez y Morales (coord.), El control de convencionalidad. Un balance comparado a 10 años de Almonacid Arellano vs. Chile (Santiago, Der Ediciones) pp. 375-402.

Hitters, Juan Carlos (2009): "Control de constitucionalidad y control de convencionalidad. Comparación (Criterios fijados por la Corte Interamericana de Derechos Humanos)", Revista Estudios Constitucionales, Año 7 (№ 2), pp. 10-128.

Nash, Claudio (2012), Derecho Internacional de los Derechos Humanos en Chile. Recepción y aplicación en el ámbito interno (Santiago, Centro de Derechos Humanos).

Nash, Claudio (2013): "Control de convencionalidad. Precisiones conceptuales y desafíos a la luz de la jurisprudencia de la Corte Interamericana de Derechos Humanos", Anuario de Derecho Constitucional Latinoamericano, Año XIX: pp. 489-509.

Nogueira, Humberto (2012): "Los desafíos del control de convencionalidad del corpus iuris interamericano para los tribunales nacionales", Boletín Mexicano de Derecho Comparado, Vol XLV, (No 135) pp. 1167-1220.

Nogueira, Humberto (2015): "El bloque constitucional de derechos en Chile, el parámetro de control y consideraciones comparativas con Colombia y México: doctrina y jurisprudencia”, Revista Estudios Constitucionales, Vol. 13, (No 2), pp. 301-350.

NúNEz, Constanza (2015): "Bloque de constitucionalidad y control de convencionalidad en Chile: avances jurisprudenciales", Anuario de Derechos Humanos, (N 11), pp. 157-169.

SAGÜÉs, Néstor (2010): "Obligaciones internacionales y control de convencionalidad", Revista Estudios Constitucionales, Año 8 (No 1), pp. 117-136.

ZúNIGA, Francisco (2017): Control de convencionalidad y tribunales nacionales. Dilemas y perspectivas, en Henríquez y Morales (coord.), El control de convencionalidad. Un balance comparado a 10 años de Almonacid Arellano vs. Chile (Santiago, Der Ediciones) pp. 489-564.

\section{JURISPRUDENCIA CITADA}

Myrna Mack Chang vs. Guatemala. Corte Interamericana de Derechos Humanos. Sentencia de fondo, reparaciones y costas, 25 de noviembre de 2003. Serie C No. 101.

Tibi vs. Ecuador. Corte Interamericana de Derechos Humanos. Sentencia de excepciones preliminares, fondo, reparaciones y costas, 7 de septiembre de 2004. Serie C No. 114.

Caso Raxcacó Reyes vs. Guatemala. Corte Interamericana de Derechos Humanos. Sentencia de fondo, reparaciones y costas, 15 de septiembre de 2005. Serie C No. 133. 
Caso lópez Álvarez vs. Honduras. Corte Interamericana de Derechos Humanos. Sentencia de fondo, reparaciones y costas, 1 de febrero de 2006. Serie C No. 141.

Almonacid Arellano y otros vs. Chile. Corte Interamericana de Derechos Humanos. Sentencia de excepciones preliminares, fondo, reparaciones y costas, 26 de septiembre de 2006. Serie C No. 154.

Trabajadores Cesados del Congreso (Aguado Alfaro y otros) vs. Perú. Corte Interamericana de Derechos Humanos. Sentencia de excepciones preliminares, fondo, reparaciones y costas, 24 de noviembre de 2006. Serie C No. 158.

La Cantuta vs. Perú. Corte Interamericana de Derechos Humanos. Sentencia de excepciones preliminares, fondo, reparaciones y costas, 29 de noviembre de 2006. Serie C No. 162.

Boyce y otros vs. Barbados. Corte Interamericana de Derechos Humanos. Sentencia de excepciones preliminares, fondo, reparaciones y costas, 20 de noviembre de 2007. Serie C No. 169.

Heliodoro Portugal vs. Panamá. Corte Interamericana de Derechos Humanos. Sentencia de excepciones preliminares, fondo, reparaciones y costas, 12 de agosto de 2008. Serie C No. 186.

Radilla Pachecho vs. Estados Unidos Mexicanos. Corte Interamericana de Derechos Humanos. Sentencia de excepciones preliminares, fondo, reparaciones y costas, 23 de noviembre de 2009. Serie C No. 209.

Comunidad Indígena Xákmok Kásek vs. Paraguay. Corte Interamericana de Derechos Humanos. Sentencia de excepciones preliminares, fondo, reparaciones y costas, 24 de agosto de 2010. Serie C No. 214.

Fernández Ortega y otros vs. México. Corte Interamericana de Derechos Humanos. Sentencia de excepciones preliminares, fondo, reparaciones y costas, de 30 de agosto de 2010. Serie C No. 215.

Rosendo Cantu y otros vs. México. Corte Interamericana de Derechos Humanos. Sentencia de excepciones preliminares, fondo, reparaciones y costas, de 31 de agosto de 2010. Serie C No. 216.

Ibsen Cárdenas e Ibsen Peña vs. Bolivia. Corte Interamericana de Derechos Humanos. Sentencia de excepciones preliminares, fondo, reparaciones y costas, 1 de septiembre de 2010. Serie C No. 217.

Vélez Loor vs. Panamá. Corte Interamericana de Derechos Humanos. Sentencia de excepciones preliminares, fondo, reparaciones y costas, de 23 de noviembre de 2010. Serie C No. 218.

Gomes Lund y otros ("Guerrilha do Araguaia”) vs. Brasil. Corte Interamericana de Derechos Humanos. Sentencia de excepciones preliminares, fondo, reparaciones y costas de 24 de noviembre de 2010. Serie C No. 219.

Cabrera García y Montiel Flores vs. México. Corte Interamericana de Derechos Humanos. Sentencia de excepción preliminar, fondo, reparaciones y costas de 26 de noviembre de 2010. Serie C No. 220.

Gelman vs. Uruguay. Corte Interamericana de Derechos Humanos. Sentencia de fondo y reparaciones, de 24 de febrero de 2011. Serie C No. 221. 
Chocrón Chocrón vs. Venezuela. Corte Interamericana de Derechos Humanos. Sentencia de excepción preliminar, fondo, reparaciones y costas, de 1 de julio de 2011. Serie C No. 227.

López Mendoza vs. Venezuela. Corte Interamericana de Derechos Humanos. Sentencia de excepción preliminar, fondo, reparaciones y costas, de 1 de septiembre de 2011. Serie C No. 233.

Fontevecchia y D`Amico vs. Argentina. Corte Interamericana de Derechos Humanos. Sentencia de fondo, reparaciones y costas, de 29 de noviembre de 2011. Serie C No. 238.

Atala Riffo y niñas vs. Chile. Corte Interamericana de Derechos Humanos. Sentencia de fondo, reparaciones y costas, de 24 de febrero de 2012. Serie C No. 239.

Furlan y familiares vs. Argentina. Corte Interamericana de Derechos Humanos. Sentencia de fondo y reparaciones, 31 de agosto de 2012. Serie C No. 246.

Masacres de Río Negro vs. Guatemala. Corte Interamericana de Derechos Humanos. Sentencia de fondo y reparaciones, 4 de septiembre de 2012. Serie C No. 250.

Masacres de El Mozote y lugares aledaños vs. El Salvador. Corte Interamericana de Derechos Humanos. Sentencia de fondo, reparaciones y costas, de 25 de octubre de 2012. Serie C No. 252.

Gudiel Álvarez y otros ("Diario Militar") vs. Guatemala. Corte Interamericana de Derechos Humanos. Sentencia de fondo y reparaciones, de 20 noviembre de 2012. Serie C No. 253.

Masacre de Santo Domingo vs. Colombia. Corte Interamericana de Derechos Humanos. Sentencia de fondo y reparaciones, 30 de noviembre de 2012. Serie C No. 259.

Mendoza y otros vs. Argentina. Corte Interamericana de Derechos Humanos. Sentencia de excepciones preliminares, fondo y reparaciones, de 14 de mayo de 2013. Serie C No. 260.

J. vs. Perú. Corte Interamericana de Derechos Humanos. Sentencia de excepción preliminar, fondo, reparaciones y costas, de 27 de noviembre de 2013. Serie C No. 275.

Liakat Ali Alibux vs. Surinam. Corte Interamericana de Derechos Humanos. Sentencia de excepciones preliminares, fondo, reparaciones y costas, 30 de enero de 2014 . Serie C No. 276.

Norín Catrimán y otros (Dirigentes, miembros y activista del Pueblo Indígena Mapuche) vs. Chile. Corte Interamericana de Derechos Humanos. Sentencia de fondo, reparaciones y costas, de 29 de mayo de 2014. Serie C No. 279.

Personas dominicanas y haitianas expulsadas vs. República Dominicana. Corte Interamericana de Derechos Humanos. Sentencia de excepciones preliminares, fondo, reparaciones y costas, de 28 de agosto de 2014. Serie C No. 282.

Rochac Hernández y otros vs. El Salvador. Corte Interamericana de Derechos Humanos. Sentencia de fondo, reparaciones y costas, de 14 de octubre de 2014. Serie C No. 285.

López Lone y otros vs. Honduras. Corte Interamericana de Derechos Humanos. Sentencia de excepción preliminar, fondo, reparaciones y costas, de 5 de octubre de 2015. Serie C No. 302. 
Comunidad Garífuna de Punta Piedra y sus miembros vs. Honduras. Corte Interamericana de Derechos Humanos. Sentencia de excepciones preliminares, fondo, reparaciones y costas, de 8 de octubre de 2015. Serie C No. 304.

García Ibarra y otros vs. Ecuador. Corte Interamericana de Derechos Humanos. Sentencia de excepciones preliminares, fondo, reparaciones y costas, de 17 de noviembre de 2015. Serie C No. 306.

Caso Chinchilla Sandoval vs. Guatemala. Corte Interamericana de Derechos Humanos. Sentencia de excepción preliminar, fondo, reparaciones y costas, de 29 de febrero de 2016. Serie C No. 312.

Caso Trabajadores de la Hacienda Brasil Verde vs. Brasil. Corte Interamericana de Derechos Humanos. Sentencia de excepciones preliminares, fondo, reparaciones y costas, de 20 de octubre de 2016. Serie C No. 318.

Miembros de la Aldea Chichupac y Comunidades Vecinas del Municipio de Rabinal vs. Guatemala. Corte Interamericana de Derechos Humanos. Sentencia de excepciones preliminares, fondo, reparaciones y costas, de 30 de noviembre de 2016. Serie C No. 328.

Andrade Salmón vs. Bolivia. Corte Interamericana de Derechos Humanos. Sentencia de fondo, reparaciones y costas, de 1 de diciembre de 2016. Serie C No. 330.

Vereda la Esperanza vs. Colombia. Corte Interamericana de Derechos Humanos. Sentencia de excepción preliminar, fondo, reparaciones y costas, de 31 de agosto de 2017. Serie C No. 341. 